\title{
Pengembangan Permainan Edukatif Pahlawan Nasional Berbasis Android
}

\author{
Andhi Setiawan ${ }^{1)}$, Rinta Kridalukmana ${ }^{2)}$, Ike Pertiwi Windasari ${ }^{2)}$ \\ Program Studi Sistem Komputer Fakultas Teknik Universitas Diponegoro \\ Jalan Prof. Sudharto, Tembalang, Semarang, Indonesia \\ Andhi.storm@gmail.com
}

\begin{abstract}
With over time the smartphone is increasingly recognized by the public, it is contrary to the interest in learning about the history of Indonesia, especially the National Hero. Because of it, the idea to combine these two, which combines the sophistication of a smartphone with a history of national hero.

Lack of instructional media on a national hero also be one of the factors that led to the creation of this application, not only can be an alternative medium of learning from the lessons of history, this application can also be one of the games that can entertain users. This application intended to provide additional knowledge about the national hero aside from the lessons taught in schools or other educational institutions, the media smartphone is well known by the public is expected that these applications can easily be accepted and may be useful for users who play this application.
\end{abstract}

Keywords: Nation Hero, Smarthphone, application, Android.

\section{Pendahuluan}

$\mathrm{T}$ EKNOLOGI di masa kini memberikan pengaruh yang sangat besar terhadap perkembangan anak. Tidak jarang ditemukan anak usia sekolah dasar sudah mahir bermain game di perangkat seluler. Melalui penelitian ini, penulis bermaksud mengembangkan permainan interaktif pada Android dengan tema pendidikan Pahlawan Nasional, selain untuk menghibur pengguna dengan permainan aplikasi ini juga bertujuan menjadi media pembelajaran dengan cara yang menyenangkan dan mudah dipahami. Karena dengan adanya permainan berbasis Android tersebut dapat mengoptimalkan penggunaan sebuah perangkat seluler yang sebagian besar hanya untuk sekedar bermain tapi juga dapat digunakan sebagai sarana pembelajaran yang sangat mudah digunakan dimanapun.

Melalui penelitian ini, penulis bermaksud membangun sebuah aplikasi multimedia pembelajaran interaktif bertema pahlawan nasional, untuk mengenalkan pahlawan nasional kepada masyarakat khususnya anak-anak dengan cara yang menyenangkan dan mudah diserap pada media perangkat seluler. Untuk itu, dengan dilakukannya penelitian ini, diharapkan dapat menjadi salah satu media pembelajaran sejarah yang menyenangkan dan mudah dipahami bagi anakanak sehingga anak-anak yang dewasa ini kerap menggunakan gadget tidak hanya menggunakannya untuk bermain permainan umum, melainkan ada unsur pendidikan di dalamnya.

\section{DASAR TEORI}

\section{A. Penelitian Terdahulu}

Dikarenakan adanya penelitian terdahulu mengenai pembelajaran sejarah dan pahlawan nasional melalui media lain selain buku, maka hal tersebut dapat menjadi acuan untuk penulis dalam mengembangkan penelitian yang sedang dikembangkan, ada beberapa acuan penulis dalam proses pembuatan aplikasi ini, yaitu diantaranya ada Game Test My History, Game G30S/PKI, dan Game Sejarah Kemerdekaan Indonesia, permainan yang disebutkan tersebut merupakan permainan yang bertema sejarah dan pahlawan nasional, dan permainan tersebut dikembangkan dengan media yang berbeda beda,seperti permainan Test My History merupakan permainan berbasis web yang hanya dapat dimainkan menggunakan koneksi internet, permainan G30S/PKI merupakan permainan yang dikembangkan dengan berbasis android, dan permainan sejarah kemerdekaan Indonesia adalah permainan yang berbasis desktop.

Ketiga permainan inilah yang menjadi acuan penulis dalam proses pembuatan aplikasi Permaian Edukatif Pahlawan Nasional. Dengan adanya penelitian terdahulu yang telah dilakukan sebelumnya penulis merasa terbantu dikarenakan penulis dapat mengembangkan pembuatan aplikasi agar berbeda dan memiliki nilai lebih dari penelitian yang sudah ada sebelumnya.

\section{B. Game (Permainan)}

Menurut Hans Daeng ${ }^{[5]}$ permainan adalah bagian mutlak dari kehidupan anak dan permainan merupakan bagian integral dari proses pembentukan kepribadian anak. Selanjutnya Andang Ismail ${ }^{[5]}$ menuturkan bahwa permainan ada dua pengertian. Pertama, permainan adalah sebuah aktifitas bermain yang murni mencari kesenangan tanpa mencari menang atau kalah. Kedua, permainan diartikan sebagai aktifitas bermain yang dilakukan dalam rangka mencari kesenangan dan kepuasan, namun ditandai pencarian menang kalah.

Game bertujuan untuk menghibur, biasanya game banyak disukai oleh anak - anak hingga orang dewasa. Game sebenarnya penting untuk perkembangan otak, untuk meningkatkan konsentrasi dan melatih untuk memecahkan masalah dengan tepat dan cepat karena dalam game terdapat berbagai konflik atau masalah yang menuntut kita untuk menyelesaikannya dengan cepat dan tepat. Tetapi game juga 
bisa merugikan karena apabila kita sudah kecanduan game kita akan lupa waktu dan akan mengganggu kegiatan atau aktifitas yang sedang kita lakukan.

\section{Pahlawan Nasional}

Secara etimologi kata "pahlawan" berasal dari bahasa Sanskerta "phala", yang bermakna hasil atau buah. Menurut Kamus Besar Bahasa Indonesia, pahlawan berarti orang yang menonjol karena keberanian dan pengorbanannya dalam membela kebenaran atau pejuang yang gagah berani. Kategori pahlawan pun ada banyak, tergantung dengan prestasi yang disumbangkannya, seperti pahlawan kemanusiaan, pahlawan nasional, pahlawan perintis kemerdekaan, pahlawan revolusi, pahlawan proklamasi, pahlawan iman, pahlawan tanpa tanda jasa, pahlawan kesiangan, dan sebagainya.

Mereka yang disebut Pahlawan Nasional ${ }^{[1]}$ adalah mereka yang Gelar Kepahlawanannya diperoleh berdasarkan Surat Keputusan Presiden RI. Para Pahlawan Nasional yang gelarnya diperoleh berdasarkan SK Presiden RI itu hingga sekarang berjumlah 163 orang. Pahlawan Nasional ${ }^{[6]}$ adalah gelar penghargaan tingkat tertinggi di Indonesia. Gelar anumerta ini diberikan oleh Pemerintahan Indonesia atas tindakan yang dianggap heroik, atau didefinisikan sebagai perbuatan nyata yang dapat dikenang dan diteladani sepanjang masa bagi warga masyarakat lainnya, atau berjasa sangat luar biasa bagi kepentingan bangsa dan negara.

\section{Sistem Operasi Android}

Android sendiri Merupakan sebuah sistem operasi yang berbasis Linux untuk telepon seluler seperti telepon pintar dan komputer tablet. Android menyediakan platform terbuka bagi para pengembang untuk menciptakan aplikasi mereka sendiri untuk digunakan oleh bermacam peranti bergerak. Secara sederhana Android dapat dikatakan ${ }^{[7]}$ merupakan software yang digunakan pada perangkat mobile yang mencakup sistem operasi, middleware, dan aplikasi kunci yang dirilis oleh google.

\section{E. Construct 2}

Construct $2{ }^{[8]}$ adalah produk buatan Scirra, perusahaan yang berasal dari London, Inggris. Construct 2 yang memang didesain dengan banyak fitur. Game builder ini sebenarnya dirancang untuk game berbasis 2D.

Construct 2 menyediakan 70 visual effect yang menggunakan engine WebGL dan juga dilengkapi dengan 20 built-in plugin dan behaviours (perilaku). Dengan begitu pengembang dapat melakukan hal-hal seperti :

a.Menambah sprite animasi

b.Objek teks

c. Mengkoneksikan ke Facebook

d.Menambah musik

e.Manipulasi penyimpanan data game

f. dan penambahan efek-efek grafis layaknya Adobe Photoshop

\section{F. Audacity}

Audacity adalah aplikasi perangkat lunak untuk merekam dan menyunting suara. Aplikasi ini bersifat open source dan sehingga dapat berjalan pada berbagai sistem operasi.

Audacity mampu mengoreksi suara tertentu, atau sekedar menambahkan berbagai efek yang disediakan. Audacity juga digunakan untuk memotong suara, menambahan bahkan mengkonversi ke file lain, diantaranya MP3, Ogg, dan Wave $9^{[9]}$.

\section{G. Corel Draw}

Corel Draw adalah sebuah program komputer yang melakukan editing pada garis vektor. Program ini dibuat oleh Corel, sebuah perusahaan software yang berkantor pusat di Ottawa, Kanada. Corel draw memiliki kegunaan untuk mengolah gambar, oleh karena itu banyak digunakan pada pekerjaan dalam bidang publikasi atau percetakan ataupun pekerjaan di bidang lain yang membutuhkan proses visualisasi $^{[10]}$.

\section{H. Metodologi Pengembangan Multimedia}

Metode yang digunakan dalam pengembangan multimedia ini adalah Multimedia Development Life Cycle ${ }^{[11]}$. Pengembangan metode multimedia ini dilakukan berdasarkan enam tahap, yaitu concept (konsep), design (rancangan), material collecting (pengumpulan materi), assembly (pembuatan), testing (pengujian), dan distribution (pendistribusian). Keenam tahap ini tidak harus berurutan dalam praktiknya, tahap-tahap tersebut dapat saling bertukar posisi. Meskipun begitu, tahap concept memang harus menjadi hal yang pertama kali dikerjakan (Luther, 1994).

Tahap pengembangannya dapat dilihat seperti pada Gambar 1 di bawah ini.

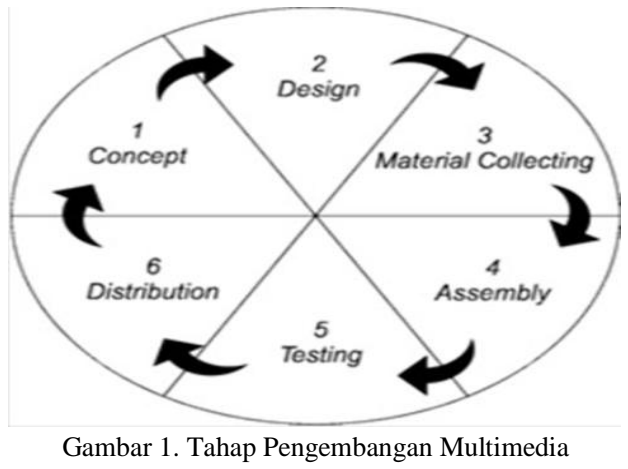

\section{Konsep (Concept)}

Dalam tahap konsep yang perlu diperhatikan adalah menentukan tujuan, termasuk identifikasi para pengguna, macam aplikasi (presentasi, interaktif, dan lain-lain), tujuan aplikasi (informasi, hiburan, dan lain-lain), dan spesifikasi umum serta memahami karakteristik pengguna. Konsep ini dapat mengacu pada kebutuhan pengguna dan kemampuan sistem dalam berkomunikasi. Selain itu, tahap ini juga akan menentukan jenis aplikasi (presentasi, interaktif, dan lain-lain). Desain (Design)

Tahap desain (perancangan) adalah membuat spesifikasi secara rinci mengenai arsitektur proyek, gaya, dan kebutuhan material untuk proyek. Menjadikan sebuah proyek menjadi sangat akurat antara teori dan yang terjadi di lapangan.

\section{Pengumpulan Materi (Material Collecting)}

Material Collecting adalah tahap pengumpulan bahan yang sesuai dengan kebutuhan yang dikerjakan. Bahan-bahan tersebut, antara lain gambar clipart, foto, animasi, video, audio, dan lain-lain yang dapat diperoleh secara gratis atau dengan pemesanan kepada pihak lain sesuai dengan rancangannya. Tahap ini dapat dikerjakan secara paralel dengan tahap assembly. Namun, pada beberapa kasus, tahap material collecting dan tahap assembly akan dikerjakan secara linear dan tidak paralel. 
Tahap pembuatan merupakan tahap pembuatan seluruh objek multimedia. Pembuatan aplikasi berdasarkan storyboard, flowchart view, struktur navigasi, atau diagram objek yang berasal dari tahap desain. Tahap ini biasanya menggunakan perangkat lunak authoring, seperti Macromedia Director. Selain itu, Macromedia Flash atau produk Open Source yang gratis, yaitu Sophie yang dapat berjalan di Linux maupun di Mac OS X juga dapat digunakan.

Pengujian (Testing)

Pengujian dilakukan setelah selesai tahap pembuatan dan seluruh data telah dimasukkan. Tahap pertama pada tahap ini disebut tahap pengujian alpha (alpha test) yang pengujiannya dilakukan oleh pembuat atau lingkungan pembuatnya sendiri. Setelah lolos dari pengujian alpha, pengujian beta yang melibatkan pengguna akhir akan dilakukan.

\section{Distribusi (Distribution)}

Bila aplikasi multimedia akan digunakan dengan mesin yang berbeda, penggandaan menggunakan floppy disk, CD-ROM, tape, atau distribusi dengan jaringan internet sangat diperlukan. Tahap distribusi juga merupakan tahap evaluasi terhadap suatu produk multimedia yang sudah jadi supaya menjadi lebih baik. Hasil evaluasi ini dapat digunakan sebagai masukan untuk tahap concept pada produk selanjutnya.

\section{PERANCANGAN Sistem}

\section{A. Konsep}

Aplikasi yang dibuat dalam penelitian tugas akhir ini bertujuan untuk membuat permainan yang berupa software berbasis android yang memuat pertanyaan mengenai pahlawan nasional. Obyek penelitian ini memiliki kategori pada jenjang sekolah dasar hingga perguruan tinggi. Pada rentang usia tersebut, seseorang sedang dalam masa aktif belajar sehingga diharapkan tujuan untuk mengenalkan dan mengingatkan tentang pembelajaran sejarah dan jasa jasa pahlawan nasional bagi Indonesia.

Konsep dasar aplikasi ini yaitu menarik dan dapat menjelaskan tentang beberapa pahlawan nasional Indonesia secara umum. Oleh karena itu digunakan perpaduan antara teks, suara dan gambar dalam merancang desain aplikasi. Pada permainan ini terdapat 4 jenis permainan, yaitu menebak nama pahlawan, menebak gambar pahlawan, puzzle dan kuis. Keempat jenis permainan ini di buat agar pemain tidak bosan dengan satu jenis permainan saja.

\section{B. Desain}

Pada tahap ini, untuk menjelaskan tahap desain aplikasi saya akan mengadaptasi penggunaan UML (Unified Modelling Language) agar dapat menjelaskan lebih jelas desain aplikasi yang akan saya buat. Desain proses dibuat berdasarkan kebutuhan fungsional dan kebutuhan data, Aliran Sistem digambarkan dengan menggunakan UML.

Diagram UML yang digunakan antara lain adalah diagram use case, Diagram use case menggambarkan fungsionalitas yang ditawarkan oleh sistem dan interaksi antara pengguna dengan sistem.

\section{Use Case Diagram}

Use case menunjukan sebuah interaksi antara user dengan sistem. Komponen utama use case diagram ini adalah user dan use case. Gambar 2 Dibawah adalah use case diagram aplikasi Pahlawan Nasional.

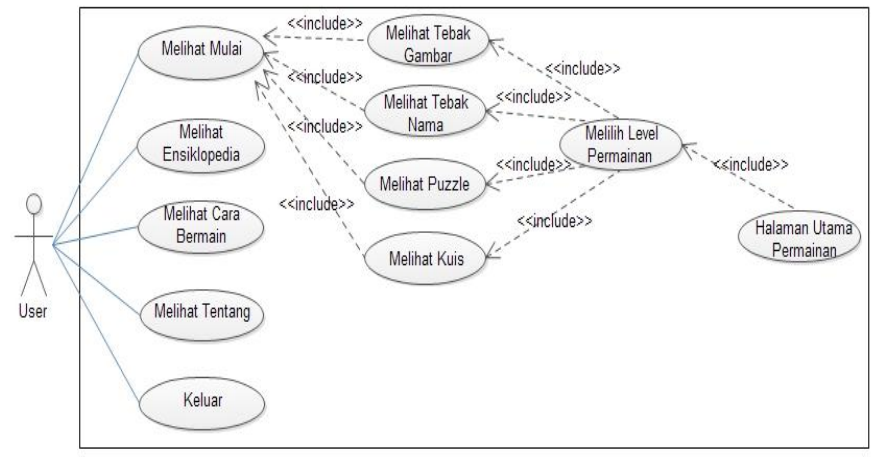

Gambar 2. Use Case Permainan Pahlawan Nasional

\section{Definisi Use Case}

Definisi Use Case berfungsi sebagai penjelasan mengenai proses yang terdapat pada setiap use case. Definisi use case diatas ini akan dijelaskan pada Tabel dibawah.

TABEL I

DEFINISI USE CASE

\begin{tabular}{|c|c|c|}
\hline No & $\begin{array}{r}\text { Nama } \\
\text { Use Case }\end{array}$ & Deskripsi \\
\hline 1 & $\begin{array}{l}\text { Melihat } \\
\text { mulai }\end{array}$ & $\begin{array}{l}\text { Pengguna mengakses menu mulai untuk masuk ke } \\
\text { dalam permainan }\end{array}$ \\
\hline 2 & $\begin{array}{l}\text { Melihat } \\
\text { Tebak } \\
\text { Gambar }\end{array}$ & $\begin{array}{l}\text { Pengguna mengakses menu tebak gambar untuk } \\
\text { memainkan permainan tebak gambar }\end{array}$ \\
\hline 3 & $\begin{array}{c}\text { Melihat } \\
\text { Tebak Nama }\end{array}$ & $\begin{array}{l}\text { Pengguna mengakses menu tebak nama untuk } \\
\text { memainkan permainan tebak nama }\end{array}$ \\
\hline 4 & $\begin{array}{l}\text { Melihat } \\
\text { Puzzle }\end{array}$ & $\begin{array}{l}\text { Pengguna mengakses menu puzzle untuk } \\
\text { memainkan permainan puzzle }\end{array}$ \\
\hline 5 & $\begin{array}{l}\text { Melihat } \\
\text { Kuis }\end{array}$ & $\begin{array}{l}\text { Pengguna mengakses menu kuis untuk memainkan } \\
\text { permainan kuis }\end{array}$ \\
\hline 6 & $\begin{array}{l}\text { Memilih } \\
\text { Level } \\
\text { Permainan }\end{array}$ & $\begin{array}{l}\text { Pengguna level permainan yang akan dimainkan } \\
\text { pada permaianan }\end{array}$ \\
\hline 7 & $\begin{array}{l}\text { Halaman } \\
\text { Utama } \\
\text { Permainan }\end{array}$ & $\begin{array}{l}\text { Fungsionalitas yang menampilkan halaman } \\
\text { permainan dan } \text { user akan menjawab pertanyaan yang } \\
\text { ada }\end{array}$ \\
\hline 8 & $\begin{array}{l}\text { Melihat } \\
\text { cara bermain }\end{array}$ & $\begin{array}{l}\text { Pengguna mengakses menu cara bermain untuk } \\
\text { mengetahui cara bermain dari aplikasi Pahlawan } \\
\text { Nasional. }\end{array}$ \\
\hline 9 & $\begin{array}{l}\text { Melihat } \\
\text { tentang }\end{array}$ & $\begin{array}{l}\text { Pengguna mengakses menu tentang dan akan } \\
\text { menampilkan penjelasan dari aplikasi Ragam Budaya } \\
\text { Nusantara }\end{array}$ \\
\hline 10 & $\begin{array}{c}\text { Melihat } \\
\text { Ensiklopedia }\end{array}$ & $\begin{array}{l}\text { Pengguna mengakses menu tentang dan akan } \\
\text { menampilkan penjelasan dari beberapa pahlawan } \\
\text { nasional }\end{array}$ \\
\hline 11 & Keluar & $\begin{array}{l}\text { Pengguna mengakses menu keluar dan keluar dari } \\
\text { aplikasi Ragam Budaya Nusantara }\end{array}$ \\
\hline
\end{tabular}

Untuk memperjelas bagaimana permainan ini dimainkan, gambar 3 dibawah adalah diagram alir dari permainan utama dari aplikasi ini. 


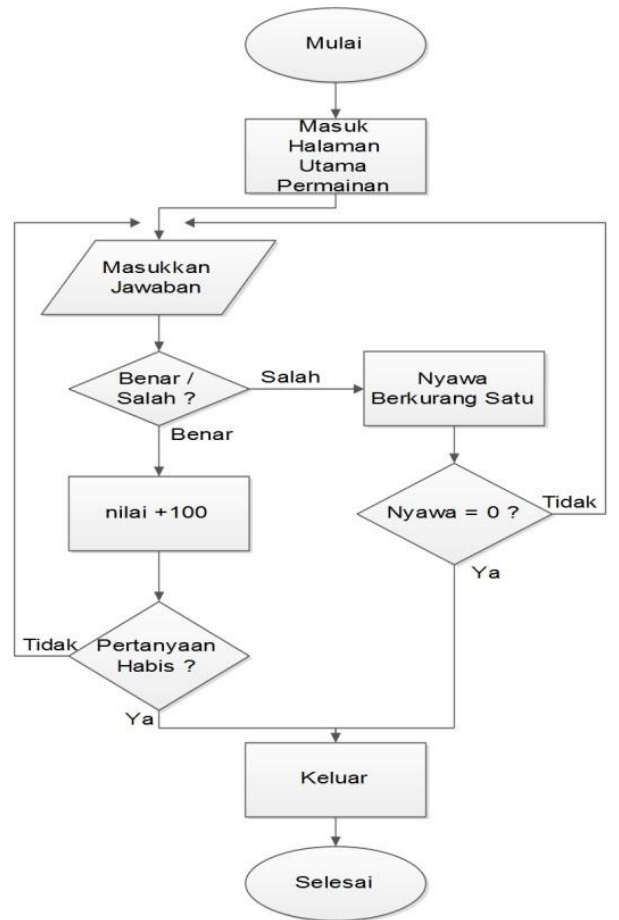

Gambar 3 Diagram Alir Pola Permainan

\section{Pembuatan Dan Pengujian}

Pembuatan permainan dilakuan dengan membuat setiap Layout dan Event sheetnya, dimulai dari Layout awal lalu di lajutkan ke Layout menu dan seterusnya secara berurutan. Pembuatan disesuaikan dengan rancangan aplikasi yang telah dibuat, serta menggunkan bahan yang telah dikumpulkan pada tahap pengumpulan bahan.

\section{Pembuatan}

Pada proses pembuatan ini penulis tidak akan menjelaskan secera detail tahap pembuatan namun akan dijelaskan garis besar dari proses pembuatannya, pembuatan aplikasi menggunakan construct 2 memiliki 3 hal pertama yang harus dibuat, yaitu layout, object dan event sheet. yang pertama adalah membuat layout untuk menempatkan object object yang akan digunakan dalam pembuatan aplikasi ini, gambar $4 \mathrm{di}$ bawah adalah gambar awal layout.

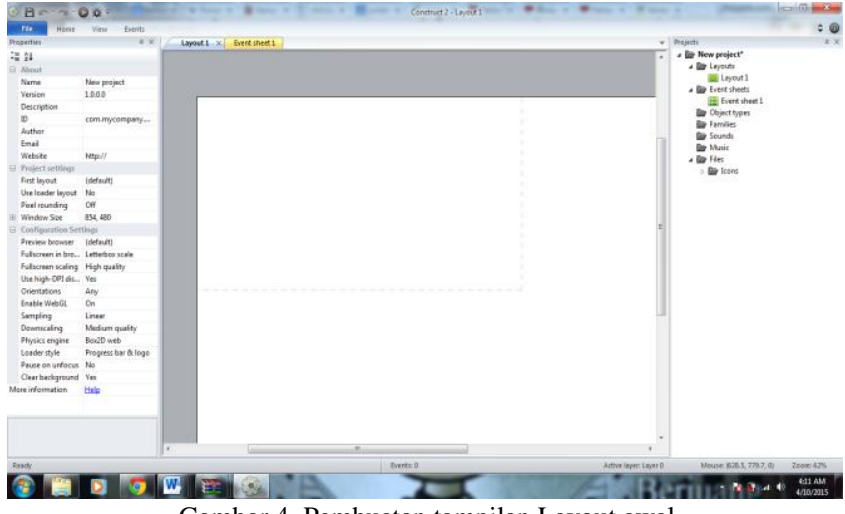

Gambar 4. Pembuatan tampilan Layout awal

Setelah itu buat object yang akan diletakkan di dalam layout yang sudah dibuat sebelumnya, object yang telah dibuat dapat dilihat seperti gambar 5 di bawah ini. $\square$ Object types

$\triangle \sqrt{ }$ awal

background

П layar

$\smile$ MULAI

teksawal

T... textAwal

$\square$ tombol

Gambar 5. Objek-objek yang terdapat pada layout awal

Setelah memasukkan objek-objek yang dibutuhkan, tahap selanjutnya adalah menyusun objek sesuai tampilan yang diinginkan. Gambar 6 merupakan gambar pembuatan tampilan pada Layout awal

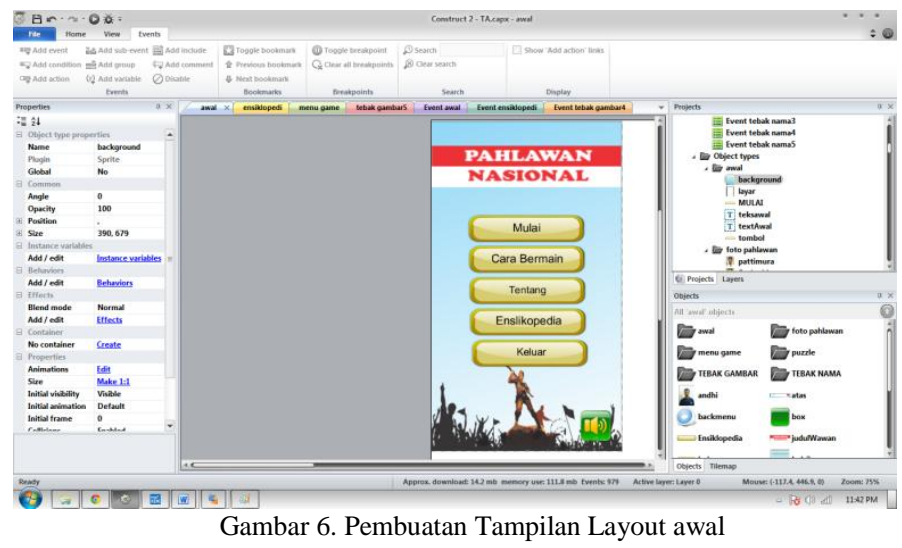

Setelah tampilan dibuat, tahap selanjutnya yaitu membuat Event untuk memberi perilaku objek-objek di Layout awal pada Event sheet Layout awal. Gambar 7 merupakan gambar pembuatan Event sheet Layout awal.

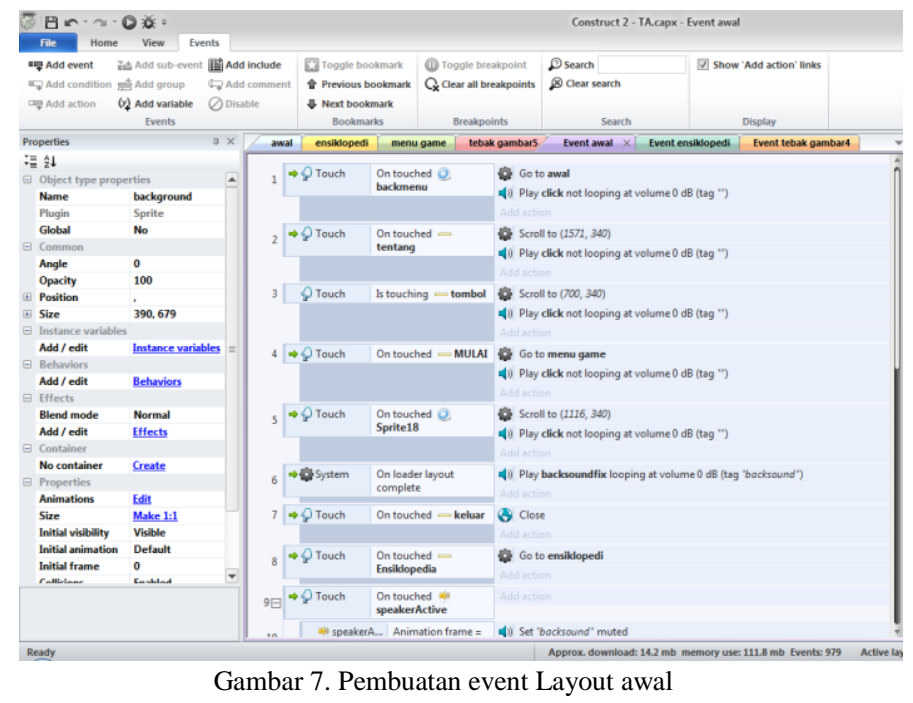

Kemudian jika objek dan Event sudah selesai, maka ketika program dieksekusi, akan muncul tampilan seperti pada Gambar 8. 


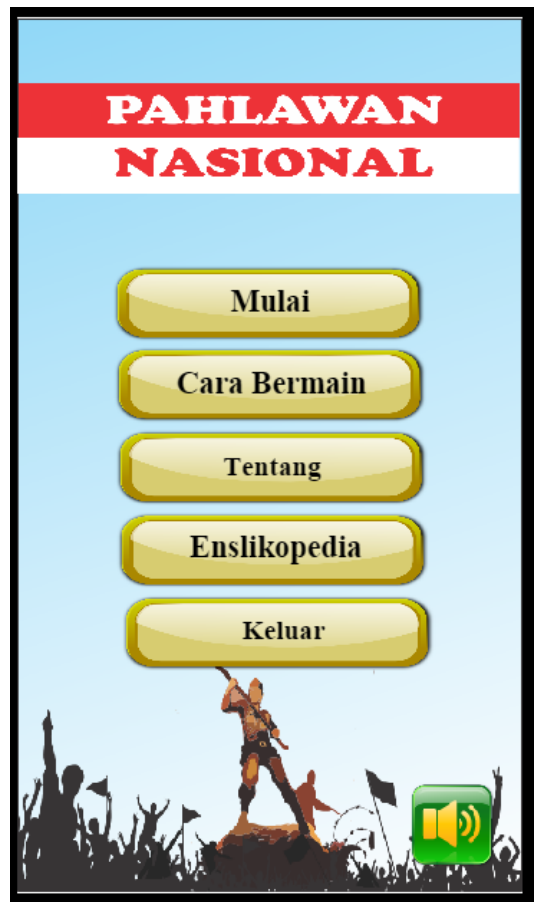

Gambar 9. Tampilan Layout awal

\section{Pengujian}

Pengujian permainan Pahlawan Nasional dilakukan dengan menggunakan metode black-box, dengan kata lain pengujian yang menekankan pada fungsionalitas dari permainan. Tahap ini berisi serangkaian pengujian fungsi dan tombol pada permainan. Tingkat keberhasilan pengujian, diukur dari terpenuhinya spesifikasi kebutuhan dan skenario permainan. Pengujian permainan dijalankan pada smartphone yang menggunakan sistem operasi Android. Cara pengujiannya hanya dilakukan dengan menjalankan permainan, kemudian diamati apakah hasilnya sesuai dengan spesifikasi kebutuhan.

TABEL II

Pengujian Aplikasi SeCARa Keseluruhan

\begin{tabular}{|l|l|l|c|}
\hline \multicolumn{1}{|c|}{$\begin{array}{c}\text { Nama } \\
\text { Pengujian }\end{array}$} & \multicolumn{1}{|c|}{$\begin{array}{c}\text { Bentuk } \\
\text { Pengujian }\end{array}$} & \multicolumn{1}{|c|}{$\begin{array}{c}\text { Hasil yang } \\
\text { Diharapkan }\end{array}$} & $\begin{array}{c}\text { Hasil } \\
\text { Pengujian }\end{array}$ \\
\hline Loading & $\begin{array}{l}\text { Membuka } \\
\text { aplikasi }\end{array}$ & $\begin{array}{l}\text { Tampilan icon loading } \\
\text { selanjutnya muncul } \\
\text { halaman awal }\end{array}$ & Berhasil \\
\hline $\begin{array}{l}\text { Pengujian menu } \\
\text { mulai }\end{array}$ & $\begin{array}{l}\text { Menyentuh } \\
\text { menu mulai }\end{array}$ & $\begin{array}{l}\text { Tampil halaman menu } \\
\text { permainan }\end{array}$ & Berhasil \\
\hline $\begin{array}{l}\text { Pengujian menu } \\
\text { cara bermain }\end{array}$ & $\begin{array}{l}\text { Menyentuh } \\
\text { menu cara } \\
\text { beramain }\end{array}$ & $\begin{array}{l}\text { Tampil halaman } \\
\text { pengantar menu cara } \\
\text { bermain }\end{array}$ & Berhasil \\
\hline $\begin{array}{l}\text { Pengujian menu } \\
\text { tentang }\end{array}$ & $\begin{array}{l}\text { Menyentuh } \\
\text { menu tentang }\end{array}$ & $\begin{array}{l}\text { Tampil halaman } \\
\text { tentang }\end{array}$ & Berhasil \\
\hline $\begin{array}{l}\text { Pengujian menu } \\
\text { ensiklopedia }\end{array}$ & $\begin{array}{l}\text { Menyentuh } \\
\text { menu } \\
\text { ensiklopedia }\end{array}$ & $\begin{array}{l}\text { Tampil halaman menu } \\
\text { ensiklopedia }\end{array}$ & Berhasil \\
\hline
\end{tabular}

\section{Distribusi Permainan}

Agar banyak pengguna dapat memainkan permainan Pahlawan Nasional ini, maka perlu dilakukan pendistribusian permainan. Tujuan dari pendistribusian permainan ini selain untuk menyebarkan permainan melalui jaringan juga untuk dapat menjadi sebuah evaluasi sehingga akan dapat mengembangkan sistem menjadi lebih baik lagi. Pendistribusian permainan ini dilakukan dengan mengupload file *apk ke media penyimpanan online seperti dropbox, mediafire dan lain lain. Kedepannya permainan ini juga akan diupload ke google play apabila aplikasi yang dibuat sudah benar benar tidak ada perubahan dan tidak memiliki bug ataupun kekurangan lainnya.

\section{KESIMPULAN DAN SARAN}

Pada bagian ini akan dijelaskan kesimpulan dan saran dari hasil penelitian dan pembahasan.

\section{A. Kesimpulan}

Kesimpulan dari penelitian Tugas Akhir ini di antaranya sebagai berikut :

1. Permainan ini dibuat menggunakan Construct 2 dan berdasarkan pengujian permainan ini dapat berjalan baik pada sistem operasi Android mulai dengan versi 2.3 (Gingerbread) sampai dengan 4.4 (kitkat).

2. Hasil dari pengujian permainan dengan menggunakan metode black-box mendapatkan hasil bahwa tomboltombol dan fungsi-fungsi yang terdapat pada permainan dapat berfungsi dengan baik dan sesuai dengan fungsionalitasnya masing-masing.

3. Permainan ini akan mengalami sedikit masalah apabila dijalankan pada perangkat berprocessor 1 $\mathrm{GHz}$ kebawah, namun akan berjalan lancar apabila dijalankan pada perangkat berprocessor diatas $1 \mathrm{GHz}$.

\section{B. Saran}

Saran yang dapat diberikan oleh penulis adalah sebagai berikut :

1. Dapat ditambahkan daftar pahlawan nasional yang lebih lengkap pada bagian ensiklopedia.

2. Dapat dikembangkan dengan menambah jumlah level yang dapat dimainkan sehingga juga memliki lebih banyak pertanyaan.

3. Dapat ditambahkan keterangan yang lebih detail pada bagian ensiklopedia agar informasi mengenai pahlawan nasional lebih lengkap dan detail.

\section{DAFTAR PUSTAKA}

[1] Katmajaya (1981). Lima Putera-Puteri Aceh Pahlawan Nasional. Yogyakarta: U.P.Indonesia

[2] ---, “TEST MY HISTORY," 2014. [Online]. Available: http://www.permainan.co.id/permainan/test-my-history/. [Diakses: 11-desember-2014].

[3] Putri, Annisa Hedlina. 2014. Pengembangan Aplikasi Multimedia Pembelajaran G30S/PKI Berbasis Android. Skripsi. Teknik Sistem Komputer. Undip. Semarang. 
[4] Jaya Umbara, Dicky dan Galih Hermawan. 2013. "Game Edukasi untuk Pembelajaran Sejarah Kemerdekaan Indonesia". Seminar on Intelligent technology and its Aplication. Surabaya.

[5] Ismail, Andang (2006). Education Games. Yogyakarta: Pilar Media.

[6] Pranadipa, Mahawira (2013). Cinta Pahlawan Nasional Indonesia. Jakarta Selatan: Wahyu Media.

[7] Solusindo, Emedia (2012). Panduan Cepat Pemrograman Android. Jakarta: Elex Media Komputindo

[8] ---, "Construct 2," 2014. [Online]. Available: http://www.scirra.com/
[Diakses: 10-oktober-2014].

[9] Setiawan, Andhi. 2013. Laporan Praktikum Multimedia 2013. Praktikum Multimedia. Universitas Diponegoro. Semarang.

[10] Perdana, Desta Arya. Pengertian dan Fungsi Corel Draw. [Online]. Tersedia: http://cyberspaceinformation.blogspot.com/2013/05/pengertian-dan-fungsicorel-draw_3451.html [Diakses : 10 desember 2014]

[11] Sutopo, Ariesto Hadi. 2012. Teknologi Informasi dan Komunikasi dalam Pendidikan. Yogyakarta: Graha Ilmu. 